\title{
Proceeding
}

Supplementary Issue: Rio 2016 Olympic Games First Anniversary Special Edition. Olympic Studies Forum, 4-5 August 2017.

Santa Úrsula University. Rio de Janeiro, Brazil

\section{Olympic Education in the Games Rio 2016: Transforma Program}

\author{
FLAVIO VALDIR KIRST ${ }^{1}$, OTAVIO GUIMARAES TAVARES DA SILVA² \\ ${ }^{1}$ Faculdades Doctum de Serra (DOCTUM), Brazil \\ 2Universidade Federal do Espírito Santo (UFES), Brazil
}

\begin{abstract}
Olympic education programs have officially been part of the Olympic Games Program since 1994. However, few of these programs are evaluated. The objective of this paper is to evaluate the Olympic education program of the organizing committee of the Rio 2016 Olympic and Paralympic Games, based on the analysis of its documents and the opinion of the education professionals who took part in it. Participants were 626 individuals who answered a semi-structured questionnaire applied electronically. We note the lack of a defined pedagogical theory, performance limited to knowledge and experience, but great capacity for articulation with public and private agencies, allowing Olympic education to reach a level never before achieved in Brazil. Finally we have elements to conclude the educational legacy in values was more clearly limited to the school environment and shows signs of discontinuity in time. Key words: OLYMPIC EDUCATION, EDUCATION IN VALUES, LEGACY, RIO 2016.
\end{abstract}

\section{Cite this article as:}

Kirst, F.V. \& Tavares da Silva, O.G. (2018). Olympic Education in the Games Rio 2016: Transforma Program. Journal of Human Sport and Exercise, 13(1proc), S86-S98. doi:https://doi.org/10.14198/jhse.2018.13.Proc1.08

\footnotetext{
Corresponding author. Universidade Federal do Espírito Santo, Centro de Educação Física e Desportos, Departamento de Ginástica. Avenida Fernando Ferrari, 514, Departamento de Ginástica Goiabeiras 29075-910 - Vitoria, ES - Brasil.

E-mail: otavio.silva@ufes.br

Supplementary Issue: Rio 2016 Olympic Games First Anniversary Special Edition. Olympic Studies Forum, 4-5 August 2017. Santa Úrsula University. Rio de Janeiro, Brazil. JOURNAL OF HUMAN SPORT \& EXERCISE ISSN 1988-5202

(c) Faculty of Education. University of Alicante doi:10.14198/jhse.2018.13.Proc1.08
} 


\section{Legado educacional dos Jogos Rio 2016: Programa Transforma}

\section{RESUMO}

Programas de educação olímpica fazem parte oficialmente do Programa dos Jogos Olímpicos desde 1994. Todavia, poucos destes programas são avaliados. 0 objetivo deste trabalho é avaliar o programa de educação olímpica do comitê organizador dos Jogos Olímpicos e Paralímpicos Rio 2016 a partir da análise de seus documentos e da opinião dos profissionais de educação que dele tomaram parte. Participaram do estudo 626 indivíduos que responderam um questionário semi-estruturado aplicado por via eletrônica. Constatamos a falta de uma teoria pedagógica definida, atuação limitada ao conhecimento e à experiência, mas grande capacidade de articulação com agências públicas e privadas, permitindo que a educação olímpica atingisse um nível nunca antes alcançado no Brasil. Por fim temos elementos para concluir que o legado educacional em valores foi mais claramente limitado ao ambiente da escola e que apresenta sinais de descontinuidade no tempo. Palavras-chave: EDUCAÇÃO OLÍMPICA, EDUCAÇÃO EM VALORES, LEGADO, RIO 2016. 


\section{INTRODUÇÃO}

Pode-se definir a Educação Olímpica como um conjunto de propostas de educação em valores por meio do esporte que tem como referência o Movimento Olímpico, seus valores, símbolos, história, heróis e tradições (Tavares, 2008). Esta definição apresenta as condições necessárias e suficientes para a demarcação entre qualquer programa educacional através do esporte e o que chamamos de educação olímpica. Se aceitarmos que valores como o fair play, por exemplo, não são exclusivos do esporte olímpico, devemos também aceitar que nem toda iniciativa de educação em valores por meio do esporte pode ser definida como "educação olímpica". Nesta linha de argumentação, o esporte é uma condição suficiente, enquanto os valores olímpicos, símbolos, histórias e tradições constituem as condições necessárias para a definição.

Todavia, o próprio criador do Movimento Olímpico, Pierre de Coubertin (2015), tinha clareza de que o esporte pode transmitir valores sociais positivos ou negativos: "Mas tanto hoje como ontem sua ação será benéfica ou prejudicial segundo o que se saiba tirar dele e a direção na qual se o estimule. 0 atletismo pode colocar em jogo as paixões mais nobres, assim como as mais vis; pode desenvolver o desinteresse e 0 sentido de honra, bem como o afã pelo lucro; pode ser cavalheiresco ou estar corrompido, ser viril ou bestial; cabe, finalmente, utilizá-lo para consolidar a paz quanto para preparar a guerra" (p.654)1.

Esta afirmativa do fundador do Movimento Olímpico é consistente com a ausência de evidências conclusivas sobre os efeitos necessariamente positivos da educação por meio do esporte (Bailey, 2005; Stegeman \& Janssens, 2004; Stigger \& Thomassim, 2013). No entanto, a falta de avaliação e evidências sólidas sobre os efeitos da educação através do esporte não tem desestimulado as preocupações do Comitê Olímpico Internacional em relação à educação olímpica. Ao contrário, pode-se encontrar na "Agenda Olímpica 2020" (International Olympic Committee, 2014) uma recomendação explícita para a educação olímpica, com 0 objetivo de incluir o esporte e seus valores nos currículos escolares em todo o mundo.

De acordo com Naul (2008), existem quatro abordagens distintas para a educação olímpica.

1. A abordagem "Orientada para o Conhecimento", que busca explicar os valores olímpicos por meio de seu legado histórico e educacional. Baseia-se principalmente nos fatos de informação e ensino (datas, nomes, histórias) do Movimento Olímpico.

2. A abordagem "Orientada para a Experiência", que enfatiza a participação em festivais esportivos e competições onde símbolos e rituais de tipo olímpico estão presentes emulando os Jogos Olímpicos.

3. A abordagem "Orientada para a Competição", que focaliza a ideia de que o desenvolvimento individual e social ocorre através da competição esportiva na presença de equidade e respeito mútuo.

4. A abordagem "Orientada para o mundo da vida" que liga os princípios olímpicos à experiência social das crianças e jovens no esporte, com as suas experiências em outras áreas das suas vidas.

O ponto de inflexão para a inserção de atividades de Educação Olímpica no programa Olímpico foi 0 Congresso Olímpico do Centenário em 1994 em Paris, quando a promoção dos ideais olímpicos como parte do processo de licitação se tornou uma demanda bem definida (Naul, 2008). Desde então, cada cidade

10 trecho citado encontra-se originalmente no texto "Le caractere de notre entreprise", publicado no Bulletin du Comité International des Jeux Olympiques, ano 1, outubro de 1894, n. 2, p. 1. 
candidata é obrigada a oferecer de alguma forma um programa educacional como parte dos Jogos. Isto colocou novos desafios para os comitês organizadores.

Investigações têm indicado que os programas educacionais de cidades olímpicas são similares em termos de objetivos, grupos-alvo, conteúdos e metodologias (Nikolaus, 2013; Tavares, 2008). Por outro lado, segundo Kohe e Chatziefstathiou (2017), uma educação em valores por meio do esporte mais significativa necessita ser coerente com os contextos particulares das vidas, identidades, interações e experiências das comunidades, grupos e indivíduos que nelas vivem. Isto significa que mesmo considerando as similaridades apontadas por Nikolaus, cada programa de educação olímpica possui suas singularidades. Todavia, estudos de avaliação destes programas são pouco conhecidos. Os relatórios de execução dos Jogos Olímpicos são bastante sucintos neste aspecto, caracterizando-se basicamente por apresentarem dados sobre os temas escolhidos, a duração do Programa, as atividades realizadas, as entidades parceiras, o número de sujeitos e instituições participantes e informações semelhantes. Neste contexto, não é possível avaliar os impactos e legados destes programas para o conhecimento sobre o Movimento Olímpico, os esportes, seus valores assim como para a mudança de atitude das pessoas que compõem seus grupos-alvo.

Assim, o objetivo deste estudo é avaliar o programa de educação olímpica do Comitê Organizador dos Jogos Olímpicos Rio 2016 a partir da perspectiva dos profissionais da educação que interagiram com o Programa. Em face da compreensão de que a prática esportiva não é naturalmente educativa e da centralidade da educação olímpica para a realização dos princípios fundamentais do Movimento Olímpico, entendemos que estudos como este podem ajudar a compreender o alcance da efetividade das iniciativas de Educação Olímpica conectadas aos Jogos Olímpicos.

\section{PROCEDIMENTOS METODOLÓGICOS}

Esta pesquisa se caracteriza como um estudo de levantamento de tipo descritivo. A amostra da pesquisa pode ser definida como probabilística, uma vez que todos os profissionais participantes do Programa tiveram chance igual e conhecida de fazer parte do estudo. Contudo, sua participação foi voluntária.

Utilizando o cadastro oficial do programa Transforma, encaminhamos um questionário semi-estruturado eletrônico validado por um painel de juízes composto de 14 questões a todos os professores presentes na base de dados. $O$ cadastro do programa Transforma é composto por um total de 14.566 endereços de correio eletrônico, sendo 6.695 cadastros de professores de educação física, 3.613 de coordenadores pedagógicos, e 4.258 pessoas cadastradas para acesso ao conteúdo digital. Após filtragem desses endereços, descobriu-se que 2.662 e-mail's estavam duplicados, de forma que, efetivamente, 11.904 diferentes endereços foram contatados. Desses, 592 endereços eletrônicos não alcançaram o destinatário e foram devolvidos pelos respectivos provedores, resultando no número total de 11.312 destinatários.

O questionário eletrônico ficou disponível para preenchimento durante 6 semanas, entre os dias 22 de agosto e 6 de outubro de 2017, período no qual 626 questionários foram respondidos. Este número de respondentes é compatível com o tamanho de amostras com margem de erro de $4 \%$ para universos de $\mathrm{n}=10.000$ e um coeficiente de confiança de $95,5 \%$.

\section{O PROGRAMA TRANSFORMA EM NÚMEROS}

O programa de Educação Olímpica dos Jogos Olímpicos Rio 2016 foi nomeado "Transforma". Sua estrutura organizacional foi composta por 7 pessoas, sendo um gerente geral e dois funcionários em cada uma das 
três sub-áreas: gestão do conhecimento, gestão de relacionamento e comunicação. A gestão do conhecimento selecionava o conteúdo, projetava e desenvolvia atividades e materiais educacionais a serem utilizados. A gestão de relações ocupava-se com o contato com os destinatários, criando estratégias para explicar como usar a ferramenta educacional que estava disponível, e a área de comunicação se preocupava com o marketing interno, buscando a linguagem apropriada para se comunicar com diferentes públicos.

Os objetivos eram permitir que crianças e jovens vivenciassem os valores olímpicos e paralímpicos, experimentassem novos esportes e entrassem em contato com os Jogos. Segundo seu relatório final (Berbat, 2017), o Transforma alcançou 16.042 escolas em 3.038 cidades de todos os estados da federação, e mais de 8 milhões de estudantes em todo o país.

Foram oferecidos cursos de 18 esportes a 2.003 professores de educação física em 180 cidades, 7 desafios escolares abordando temas relacionados aos Jogos do Rio (1.771 escolas em 713 cidades) e materiais pedagógicos distribuídos em formações presenciais e, principalmente, através de uma plataforma de ensino à distância para três públicos específicos: coordenadores pedagógicos escolares $(n=4942)$, professores de educação física $(n=9299)$ e tutores de agentes jovens $(n=7103)$. Foram formados 56.824 agentes jovens, crianças que atuaram como disseminadores dos valores olímpicos em suas escolas. Além disso, o programa organizou 24 festivais esportivos para a experimentação de esportes olímpicos e paralímpicos envolvendo 20.627 participantes. Finalmente, seu material digital foi baixado 63.350 vezes por 10.960 professores, que atendem a 8.812 escolas de 2.320 cidades.

Apesar de seus números impressionantes, é importante identificar a orientação teórica que apoia 0 programa. De acordo com o gerente geral de educação (V. Berbat, entrevista pessoal, 20 de julho, 2016), não havia serviços consultivos externos ou nacionais para o desenvolvimento do programa. Alguns membros do Comitê Organizador Rio 2016 foram a Londres em 2012 para conhecer o programa Get Set, mas nenhum deles mais tarde compôs a equipe do Transforma. Posteriormente, no mesmo ano, o comitê organizador decidiu estruturar uma equipe interna para montar o programa, com pessoas especializadas na área educacional. Segundo a gerente de conhecimento do Transforma (V. Fonseca, entrevista pessoal, 25 de julho, 2017), em 2012 realizou-se uma ampla pesquisa dos programas educacionais dos Jogos Olímpicos anteriores, dos quais se extraíram várias ideias e modelos para composição do conteúdo, mas não do formato, em virtude da peculiaridade, complexidade e necessidades do modelo educacional brasileiro. Em 2013 foi instituída a equipe operacional do programa e decidiu-se que seu escopo deveria ser nacional, e o ensino fundamental e médio foram escolhidos para ser o público-alvo.

O desenvolvimento da abordagem educativa do programa foi feito em três etapas: 1 - uma extensa pesquisa de material didático olímpico destinado ao uso escolar, produzido em todo o mundo, 2 - tradução e adaptação do material já disponível, 3 - uso de materiais existentes e produção de novos materiais que se fizessem necessários.

Durante a pesquisa de referência foram realizados dois estudos piloto para testar as estratégias de projeto e ação. Esses estudos indicaram a necessidade de não restringir o grupo-alvo aos professores de educação física, pois neste modelo não havia integração escolar como um todo. Assim, coordenadores pedagógicos foram treinados e encorajados a integrar os Jogos Rio 2016 em diversas disciplinas escolares, enquanto os professores de Educação Física promoviam a experimentação de diferentes esportes olímpicos e paralímpicos como estratégia de educação em valores (V. Berbat, entrevista pessoal, 20 de julho, 2016). 
As ações para dar proporções nacionais ao Transforma envolveram o estabelecimento de parcerias com 0 Ministério da Educação e os conselhos estaduais e locais de educação e o Conselho Federal de Educação Física. $O$ envolvimento dessas entidades foi bastante variado, mas pode ser considerado um sucesso, visto ser o Brasil um país que está apenas em vias de implementar um currículo nacional. Uma das razões para este sucesso pode estar relacionada com a generalidade formal das informações (os seus objetivos eram permitir que crianças e jovens os vivenciassem valores olímpicos e paralímpicos, experimentassem novos esportes e entrassem em contato com os Jogos), o que permitiu que muitas instituições diferentes se juntassem ao programa sem compromissos educacionais mais detalhados. Um dos resultados mais importantes dessas parcerias foi o uso compartilhado da plataforma de educação federal online "e-Proinfo", oferecendo todos os cursos sem o custo adicional de implementar um novo sistema.

Uma quarta parceria foi estabelecida com as 65 confederações esportivas olímpicas e paralímpicas. 0 desafio aceito pelas confederações foi a apresentação e 0 ensino de seus esportes nas escolas. Coube às confederações a criação de material simplificado para o ensino de seus respectivos esportes, com o uso de materiais alternativos e o ensino em 10 etapas simples, que através de aulas de vídeo e material escrito, estavam disponíveis para os professores de educação física. Finalmente, em 2016, foi estabelecida outra parceria com a TV Escola para lançar um talk show semanal, sempre com dois entrevistados, sendo um atleta e um professor, num diálogo sobre o tema valores, sua importância na vida do atleta e como pode ser trabalhado na escola.

\section{IMPACTOS DO PROGRAMA TRANSFORMA: APRESENTAÇÃO E DISCUSSÃO DOS RESULTADOS}

Quanto ao perfil dos respondentes, $58 \%$ são do sexo feminino e $42 \%$ do sexo masculino. Conforme exposto no gráfico 1, a maior parte da amostra é composta por professores de educação física, $66,3 \%$ do total, $17,7 \%$ são coordenadores pedagógicos, $7,8 \%$ professores de outras disciplinas, 2,7\% funcionários administrativos das escolas e $5,4 \%$ não se enquadram em nenhum desses grupos (outros), o que provavelmente representa um número de sujeitos que se cadastrou de forma equivocada no programa.

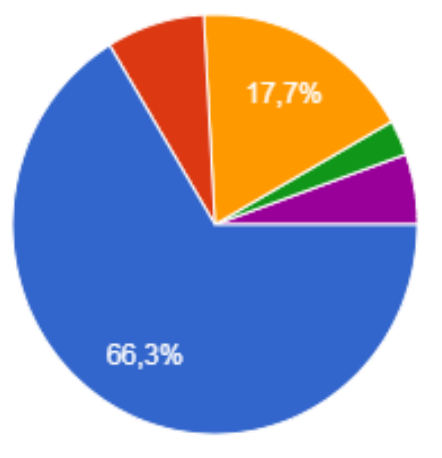

Professor de Educação Física

Professor de outras disciplinas

Coordenador Pedagógico

Funcionário administrativo da escola

Outros

\section{GRÁFICO 1. Cargo exercido na escola}

Esse dado corrobora com o que afirmou o gerente geral de educação do comitê organizador dos Jogos, Vanderson Berbat, segundo o qual os professores de educação física foram os grandes impulsionadores do Transforma. Esta prevalência de professores de educação física pode estar relacionada ao fato que existem mais professores de educação física do que coordenadores pedagógicos no sistema escolar. Por outro lado, tais dados indicam que apesar do programa ter objetivado envolver toda a escola, a disciplina a educação 
física parece ter sido a unidade curricular que mais se envolveu com o programa, o que pode ser explicado pelo caráter central do esporte nas ações do Transforma.

Quanto ao grau de formação alcançado, $64,2 \%$ possuem especialização, $7 \%$ mestrado e $0,6 \%$ doutorado, enquanto que $27 \%$ concluíram apenas o ensino superior. Por outro lado, pessoas que possuem o ensino fundamental e médio somam juntos 1,2\%. Este elevado nível de escolarização e capacitação dos profissionais que participaram do Transforma indica um nível igualmente mais elevado de compreensão, apropriação e crítica do Programa.
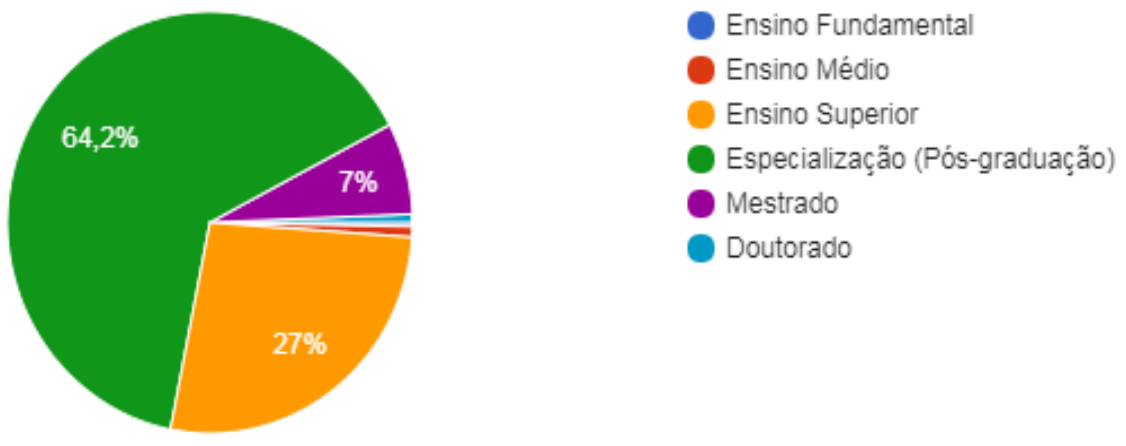

GRÁFICO 2. Maior grau de formação

Apesar do programa Transforma ter iniciado suas ações em 2013, apenas 3\% dos respondentes começou a participar naquele ano. Sua expressividade em nível nacional foi aumentando gradativamente nos anos 2014 (6,4\%), 2015 (29,4\%) e, principalmente, em 2016, ano em que 61,2\% dos respondentes iniciou seu acesso ao programa (Gráfico 3). Tais dados não só são coerentes com a crescente visibilidade dos Jogos Olímpicos do Rio à medida em que a data de abertura se aproximava, como também são compatíveis com o próprio aumento das atividades do Programa ano a ano.

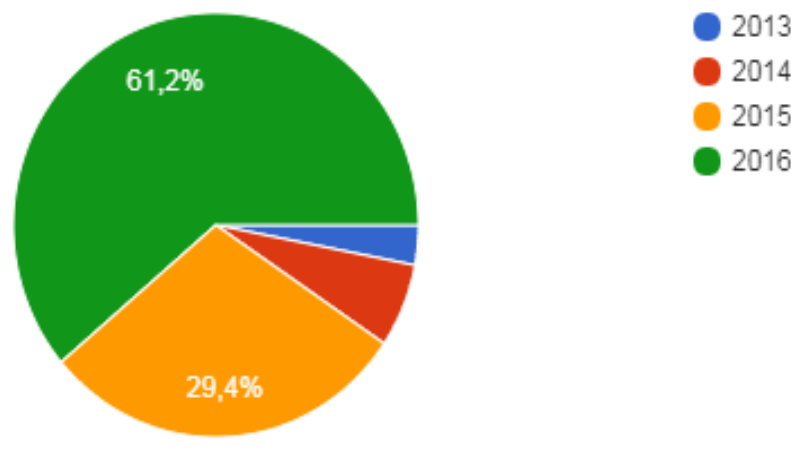

GRÁFICO 3. Ano em que começou a receber treinamento / baixar documentos / desenvolver atividades do programa Transforma

Quando perguntados sobre "como você conheceu o Transforma?", diversos foram os meios citados, no entanto, destacaram-se nessa divulgação as esferas locais, estaduais e nacionais de gestão escolar. As secretarias de educação foram indicadas por 31,9\%, a plataforma de educação online do Ministério da 
Educação, e-Proinfo, por 20,6\%, a coordenação pedagógica da escola por $11,7 \%$. Juntas totalizaram $64,2 \%$ do total de respostas. $22 \%$ dos respondentes tomaram conhecimento do programa pesquisando na internet, $7 \%$ receberam indicação do programa por um colega professor, e apenas $4 \%$ foram contatados diretamente pela equipe do Transforma. Esse dado dá conta de que as parcerias firmadas pelo Transforma, sobretudo com as esferas educacionais do poder público, foram fundamentais para o sucesso e a expansão do programa, tornado-se os parceiros seus principais veículos de divulgação.

Em relação aos tipos de atividades das quais participaram (a questão permitia múltiplas respostas), a maioria dos respondentes teve acesso ao Transforma através de plataformas digitais. $62,6 \%$ acessaram o conteúdo digital, diretamente no site do Transforma. Utilizando a plataforma e-Proinfo, 42,3\% realizaram a formação para professores de educação física, 20,9\% a formação para coordenadores pedagógicos e $12,5 \%$ a formação para tutores de agentes jovens. Além disso, 27,2\% envolveram suas escolas no Desafio Transforma, gincana que envolvia a realização de tarefas relacionadas aos jogos e símbolos olímpicos, viabilizada através do site do Transforma. A tabela 1 compara o percentual de participação nas atividades presenciais e à distância.

TABELA 1. Participação nas atividades desenvolvidas pelo programa Transforma²

\begin{tabular}{ccc}
\hline ATIVIDADE & PRESENCIAL & À DISTÂNCIA \\
\hline Capacitação Esportiva & $16,3 \%$ & - \\
Desafios Escolares & - & $27,2 \%$ \\
Festivais Esportivos & $6,2 \%$ & - \\
Conteúdo Digital & - & $62,6 \%$ \\
Formação para Coordenadores Pedagógicos & $7 \%$ & $20,9 \%$ \\
Formação para Professores de Educação Física & $10,4 \%$ & $42,3 \%$ \\
Formação para tutores de agente jovem & $3,7 \%$ & $12,5 \%$ \\
\hline
\end{tabular}

Em resumo, podemos afirmar que o "tipo ideal" de usuário do Transforma foi o professor de educação física, especialista (pós-graduado), que conheceu o programa no ano da realização dos Jogos, em 2016, por intermédio das agências públicas de educação, e fez uso de materiais disponibilizados através de plataformas digitais, principalmente 0 site do Transforma e o e-Proinfo.

$\mathrm{Na}$ questão de número 7, solicitamos aos respondentes que "a partir do material e/ou formação aos quais teve acesso no Transforma, nas questões a seguir, indique qual é o seu nível de conhecimento ${ }^{3}$ do tema", todas as categorias tiveram avaliação positiva, com a maior concentração de respostas incidindo sempre entre os graus 4 e 5 . Impressiona o nível de conhecimento declarado pelos respondentes do tema "valores olímpicos", com 47,6\% indicando conhecimento total (grau 5), e 34,8\% o grau 4, que juntos somam 82,4\% das respostas. Esse resultado é seguido de perto pelo tema "esportes olímpicos", onde 31,6\% indicaram 0

2 Os campos marcados com traço (-) indicam atividades não ofertadas nessa modalidade.

3 Utilizamos uma escala de atitudes de 1 a 5 , onde "1" significa desconhecimento total e " 5 " significa conhecimento total do tema. 
grau de conhecimento 5 , e 48,6\% o grau 4, que juntos somam $80,2 \%$ das respostas, e pelo tema "símbolos olímpicos", com $43,3 \%$ e $36,1 \%$, respectivamente, que somam juntos $79,4 \%$. É importante observar ainda que nos graus inferiores, que indicam desconhecimento total dos temas, o percentual foi extremamente baixo, e nenhum deles ultrapassou $8,1 \%$ (somados os graus 1 e 2). 0 resultado completo pode ser observado no gráfico 4.

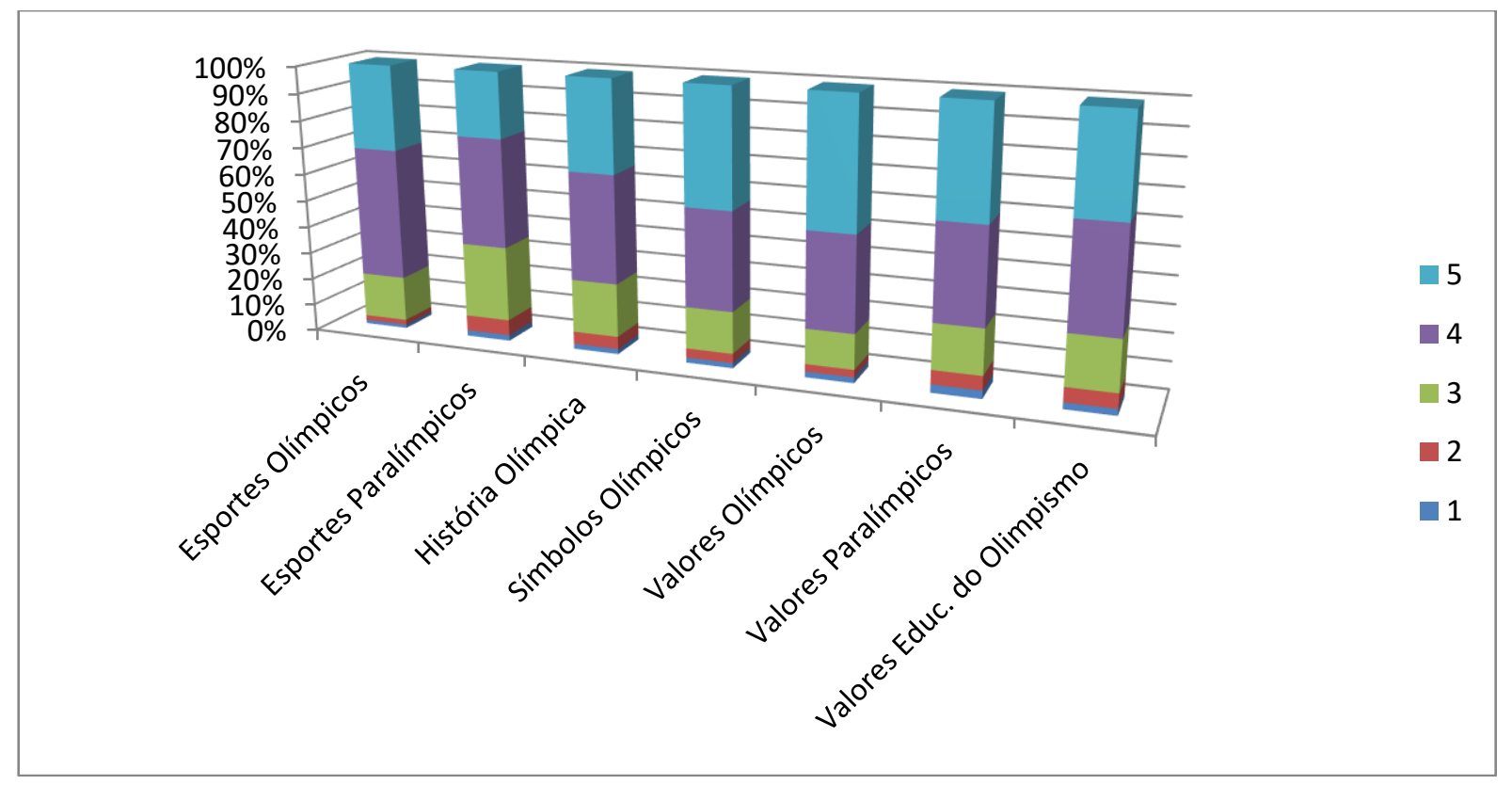

GRÁFICO 4. Nível de conhecimento dos temas

Embora não tenha sido feita nenhuma testagem objetiva, o elevado grau de conhecimento dos temas, atribuído pelos respondentes ao trabalho desenvolvido pelo Transforma, indica que suas ações educacionais podem ser consideradas um case de sucesso em Estudos Olímpicos.

Objetivando averiguar as ações resultantes da participação dos professores no programa Transforma, a questão seguinte solicitava ao respondente: "assinale as ações desenvolvidas na escola como resultado de sua participação no programa Transforma". Os resultados corroboram com os obtidos na questão anterior e, novamente os valores olímpicos tiveram o maior destaque (categoria "ensino dos valores olímpicos"), indicados por $80,5 \%$ dos respondentes, seguido por "ensino de novos esportes" com 72,8\%, e "ensino de símbolos olímpicos" $70,4 \%$. Outras duas ações tiveram importante destaque, dada a conhecida necessidade de mobilização de toda a escola para sua realização: a "realização de jogos olímpicos na escola", indicada por $54 \%$ dos respondentes, e a "participação nos desafios escolares propostos pelo Transforma", por 38,3\%. As respostas indicaram ainda que as atividades presenciais oportunizadas pelo Transforma, como a viabilização da participação de alunos a eventos-teste, aos Jogos Olímpicos e aos Jogos Paralímpicos do Rio de Janeiro, ficaram abaixo dos $8 \%$, o que pode ser explicado por tratar-se de ações que envolveram principalmente escolas do Rio de Janeiro.

A questão 9 indagava sobre o número total de estudantes que foram envolvidos nas ações desenvolvidas na escola. Houve predominância nos grupos de "até 100" (28,1\%) e "de 100 à 200" (23\%) alunos, seguidos de perto pelo grupo "de 200 à 300" alunos (19,3\%). Juntos esses três grupos ultrapassam 70\% da amostra. 
Nos grupos maiores observa-se gradativa redução: 11,5\% envolveram "de 300 à 400" alunos, 6,2\% "de 400 à 500", e 11,8\% envolveram "mais de 500" alunos. Esses dados estão ilustrados no gráfico 5 .

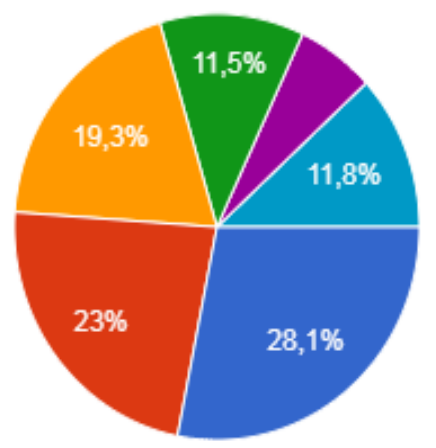

Até 100

De 101 à 200

De 201 à 300

De 300 à 400

De 400 à 500

Mais de 500

GRÁFICO 5. Número de estudantes da escola envolvidos nas atividades

$\mathrm{Na}$ questão 10 os respondentes foram convidados a manifestar sua opinião 4 sobre o quanto objetivos do programa Transforma foram alcançados em sua escola. Novamente observa-se uma avaliação bastante positiva, com todos os objetivos apontados como totalmente alcançados (considerando os graus 4 e 5 ) por mais de $60 \%$ dos respondentes. 0 contato com os jogos e a experimentação de novos esportes foram os mais bem avaliados, somando 67,1 e 64,8\%, respectivamente. Com base nesses dados, é possível afirmar que os objetivos inicialmente traçados pelo Transforma foram alcançados com êxito, o que por certo, está relacionado à sua generalidade formal e baixo nível de detalhamento. 0 gráfico 6 traz os dados completos.

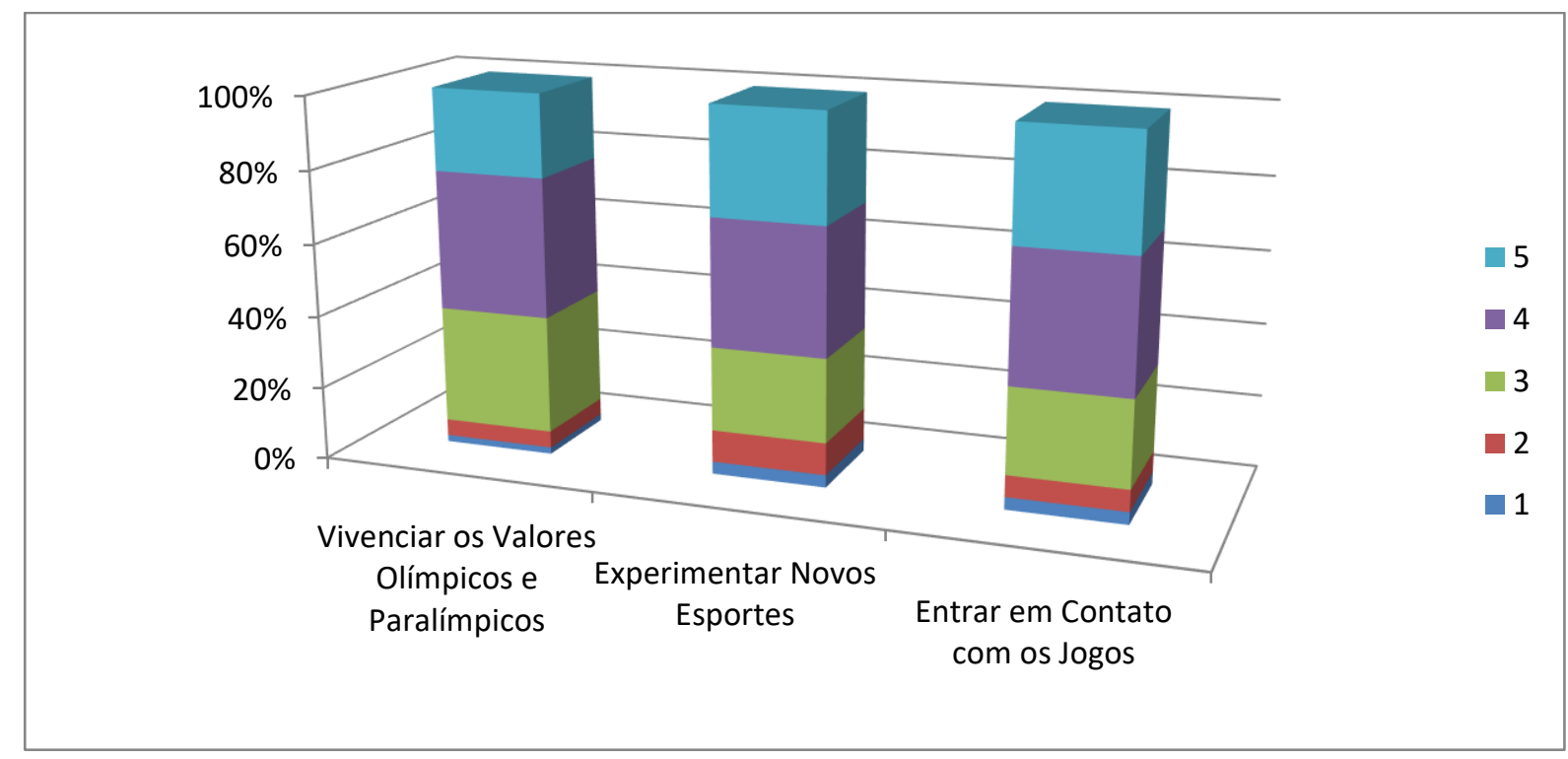

GRÁFICO 6. Nível de alcance dos objetivos do programa Transforma

No que se refere aos impactos ocorridos na escola em decorrência das ações do programa Transforma, pode ser observado no quadro a seguir que ao indicarem o nível de concordância ${ }^{5}$ com as afirmações, três

4 Utilizamos uma escala de atitudes de 1 a 5 , onde "1" significa não alcançado e "5" significa totalmente alcançado.

5 Utilizamos uma escala de atitudes de 1 a 5 , onde "1" significa discordo totalmente e " 5 " significa concordo totalmente. 
delas destacaram-se no que tange a impactos positivos: "os alunos aprenderam novos esportes olímpicos", "os alunos aumentaram seu conhecimento sobre os Jogos Olímpicos", e "os alunos aprenderam os valores olímpicos". Considerando apenas os graus 4 e 5 , todas apresentaram em torno de $80 \%$ de concordância dos respondentes. Apesar de reconhecerem que houve mudança comportamental dos alunos em decorrência das atividades realizadas, o nível de concordância com essas afirmações se desloca na direção do grau 3 (concordância parcial), o que pode ser observado (gráfico 7) nos tópicos que abordam a melhora comportamental dentro e fora da escola e a utilização dos valores olímpicos e paralímpicos no "mundo da vida". Tais resultados não surpreendem. Em primeiro lugar, parecem estar relacionados com o número pequeno de atividades "orientadas para o mundo da vida" (Naul, 2008). Além disto, conhecer valores não significa necessariamente acolhe-los ou comportar-se de acordo com eles. Como sabemos, práticas educacionais coletivas como são aquelas vividas nas escolas, dificilmente apresentariam resultados uniformes. Assim, é bastante compreensível o resultado encontrado.

Observa-se ainda a predominância no aprendizado de esportes e valores olímpicos em relação a esportes e valores paralímpicos, o que pode estar relacionado à maior popularidade e acessibilidade dos esportes olímpicos em relação aos paralímpicos no Brasil.

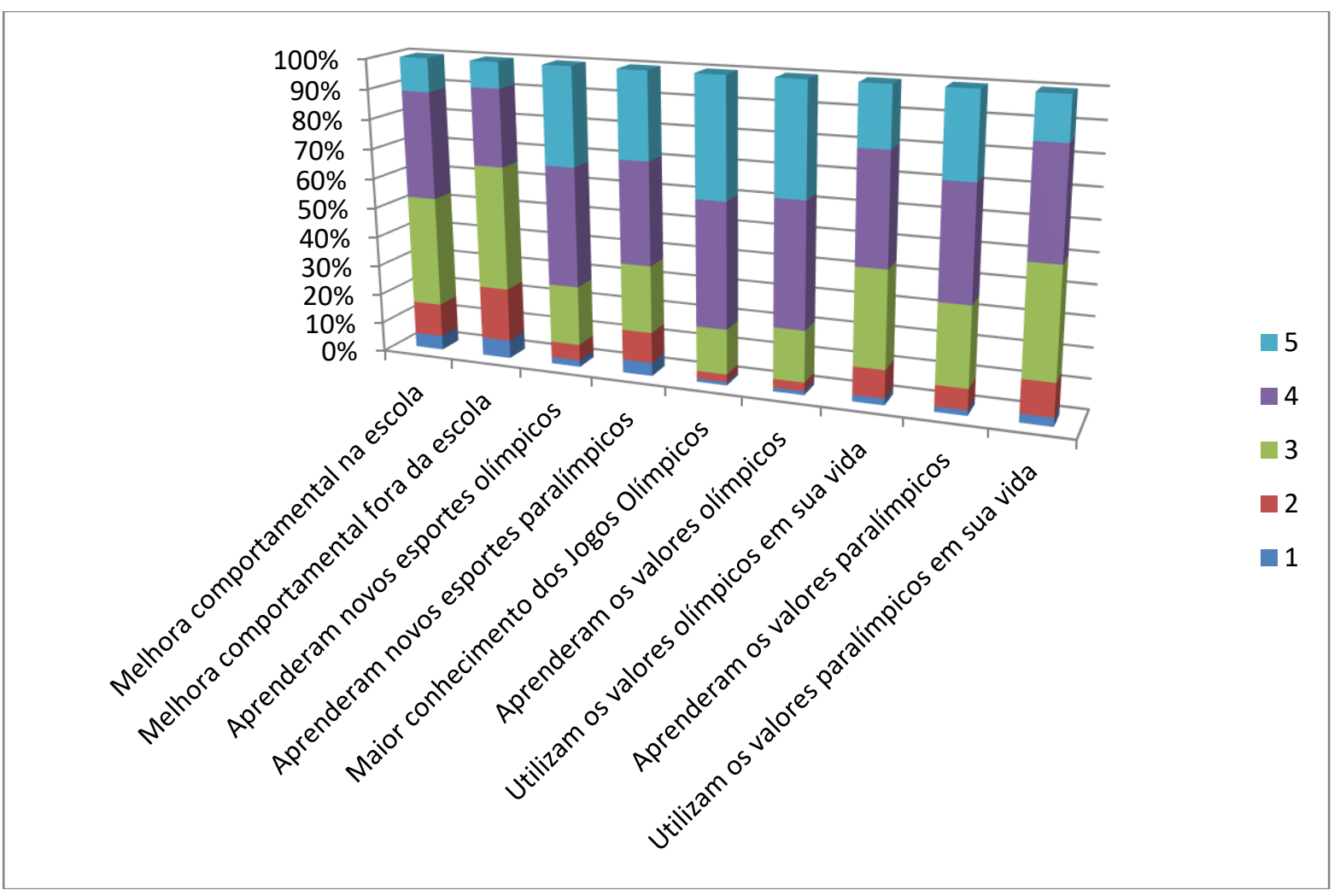

GRÁFICO 7. Impactos percebidos nos alunos em decorrência das ações do programa Transforma

$\mathrm{Na}$ questão de número 12 perguntamos "qual foi a melhor experiência ${ }^{6}$ proporcionada pelo Programa Transforma na sua escola?". Os grandes destaques foram o "ensino de valores olímpicos e paralímpicos", opção de $36,1 \%$ dos respondentes, o "ensino de novos esportes", indicado por $24,9 \%$, e "realização dos

60 respondente poderia escolher uma só alternativa. 
jogos olímpicos na escola", para 18,8\%. Para 8,9\% dos respondentes a melhor experiência foi a "participação nos desafios escolares propostos pelo Transforma".

Os dados revelados nas questões 11 e 12 reforçam os resultados da questão 10, e confirmam o sucesso alcançado pelo Transforma em relação aos objetivos declarados.

Por fim, questionamos os participantes da pesquisa sobre a continuidade da utilização dos materiais disponibilizados e realização das ações propostas pelo programa Transforma. Um ano após o término do programa, 58,5\% dos respondentes afirmam que já não utilizam mais, e 41,5\% dizem continuar utilizando os materiais e atividades propostas. Dentre os materiais indicados como ainda em uso, destacam-se 0 conteúdo digital baixado ${ }^{7}$ (download) e o ensino de novos esportes. Com base nesse dado, pode-se afirmar que existe um legado educacional ainda em curso, fruto dos esforços individuais dos professores que participaram do programa. Este fato já havia sido previsto pelo gerente geral de educação Vanderson Berbat em 2016, quando afirmou que "a continuidade do trabalho de educação olímpica proposto pelo Transforma depende em grande medida dos professores que foram atingidos pelo programa, replicando e aprofundando o tema por iniciativa própria".

\section{CONSIDERAÇÕES FINAIS}

A partir dos dados levantados pode-se dizer que não havia uma teoria pedagógica definida orientando as ações do Transforma, tendo como consequência o padrão de seleção eclética de referências. Ainda não está claro se esta foi uma decisão intencional e as razões para isso.

As ações tomadas pelo Programa podem ser caracterizadas como abordagens "orientadas para 0 conhecimento" e "orientadas para a experiência". Pequenas atividades como os desafios escolares, podem ser definidas como uma abordagem "orientada para o mundo da vida". A abordagem de ensinar valores através do esporte supõe que o esporte é educativo por natureza, não necessitando de uma teoria de apoio educacional. Como mostramos no início deste texto, esta é uma visão problemática do esporte como uma ferramenta educacional desde tempos de Coubertin.

Por outro lado, a generalidade formal dos objetivos, a ausência de uma teoria pedagógica definida de educação em valores e a falta de currículo nacional no Brasil parece ter permitido ao Transforma seu alcance nacional, uma vez que sua ação encontrou poucas barreiras intelectuais para prosperar. Neste contexto, a aula de educação física e o professor de educação física continuaram a ser os agentes principais da educação olímpica nas escolas.

Tão importante quanto a generalidade formal do Transforma foi sua capacidade de diversificar estratégias e parcerias. 0 número de pessoas atingidas deve-se às múltiplas estratégias adotadas pelo programa, combinando atividades de treinamento presencial com a disponibilidade de livretos, aulas digitais, livros e vídeos de instrução através do site e dos múltiplos parceiros, para ser acessível a escolas em todo o país a baixo custo. Outra conclusão que pode ser extraída desta experiência de educação olímpica foi a sua capacidade de articulação com várias agências públicas e privadas para atingir seus objetivos, além de sua capacidade de usar vários meios para a entrega de seu conteúdo educacional. Neste contexto, e conhecimento dos valores olímpicos e seus símbolos, assim como de novos esportes provavelmente atingiu um nível nunca alcançado antes no Brasil.

7 Textos, aulas, vídeos, entre outros. 
Por outro lado, a falta de definição teórica, suas ambições de alcance nacional e até mesmo a duração limitada de sua operação sugere os limites do legado do Transforma em termos de educação de valores. Não só não existem indicadores elevados dos efeitos do Programa para a vida em sociedade, como também, há um ano dos Jogos, cerca de metade dos profissionais que participaram do Transforma já deixaram de usar seus materiais pedagógicos. Talvez esta seja uma característica que todos os programas educacionais vinculados aos Jogos Olímpicos precisam aceitar.

\section{REFERÊNCIAS}

Bailey, R. (2005). Evaluating the relationship between physical education, sport and social inclusion. Educational Review. 57:1, p. 71-90. Retrieved from: https://doi.org/10.1080/0013191042000274196 Berbat, V. (2017). Transforma: Relatório final. Documento cedido por Vanderson Berbat. Rio de Janeiro. Coubertin, P. (2015). Olimpismo: seleção de textos. Lausanne, Porto Alegre: Comitê Internacional Pierre de Coubertin, EdiPUCRS. (Obra Original Publicada 1986).

International Olympic Committee (2014). Olympic Agenda 2020. Lausanne: IOC.

Kohe, G. Z., \& Chatziefstathiou, D. (2017). London 2012: Olympic education in the United Kingdom rethinking London 2012, learning 'legacies' and their pedagogical potential. In: Naul, R.; Binder, D.; Richtecky, A.; Culpan, I. (Eds.) Olympic Education: An international review (pp. 60-72). London/New York: Routledge.

Naul, R. (2008). Olympic Education. Frankfurt: Meyer \& Meyer.

Nikolaus, I. (2013). Pierre de Coubertin's Olympic Idea as an Educational Challenge for the Worldwide Olympic Movement. Kassel: Sportverlag.

Stegeman, H., \& Janssens, J. (2004). Introdution. In: JANSSENS, J. et al. (Orgs) Education through sport. Amsterdan: Mullier Institute.

Stigger, M. P., \& Thomassim, L. E. (2013). Entre o 'Serve' e o 'Significa': Uma análise sobre expectativas atribuídas ao esporte em projetos sociais. Licere, 16:2.

Tavares, O. (2008). Olympic Education in Rio de Janeiro: Notes to develop a model. In: DaCosta, L. P. et al. (Orgs) Legacies of Sports Mega-Events (pp. 343-356). Brasília: Ministério do Esporte.

\section{(9) $(\mathcal{\Theta \Theta}$}

This title is licensed under a Creative Commons Attribution-NonCommercial-NoDerivs 3.0 Unported License. 